\title{
Variations in lengths of stay and rates of day case surgery: implications for the efficiency of surgical management
}

\author{
Myfanwy Morgan, Roger Beech
}

\begin{abstract}
Variability in lengths of acute hospital stay and rates of day case surgery is shown to be a continuing pattern which occurs both between and within countries. $A$ model of the determinants of health service activity is presented and the contribution of different factors to the observed variations is assessed. Differences in methods of funding health services are identified as a major determinant of the between country variations, while the within country variations largely reflect the influence of local differences in facilities and services and the organisation of care at a hospital level, as well as the independent effects of differences in clinical practice style.
\end{abstract}

The main rationale for advocating a reduction in length of stay and increased use of day surgery is to increase efficiency by reducing costs per case while maintaining the quality of care. These criteria of costs, clinical outcomes and patient acceptability are examined in relation to day case surgery for an intermediate surgical procedure (inguinal hernia repair) and short stay surgery for cholecystectomy. The precise cost savings are shown to depend on the methods of costing, assumptions made and facilities employed, while factors influencing the outcomes achieved include the criteria of patient selection, the surgical techniques employed, and the adequacy of preoperative communication. Barriers to the more widespread adoption of short stay and day case surgery include practical and organisational constraints on clinical practice at a hospital level, lack of awareness among clinicians as to how far their practices differ from current norms, and clinical barriers raised by surgeons who do not see short stay policies as advantageous. Mechanisms to promote changes in clinical practice styles include independent professional audit, peer review, and involvement of clinicians in budgeting and resource allocation. Assessing quality requires that attention is given to patient acceptability and satisfaction as well as to the monitoring of clinical outcomes.

An important feature of health service activity is the variation which occurs between geographical areas and between individual clinicians. This includes variations at a primary care level in terms of general practitioner referral rates, prescribing rates and ordering of diagnostic tests. ${ }^{12}$ In the hospital sector particular attention has been paid to the variations in hospital admission rates, which form a major determinant of health service costs. This has identified substantial variations in admission rates between countries, with rates of admission for surgical procedures generally being higher in the US than the UK, although there are also large within country variations. ${ }^{3-7}$ This paper focuses on two other indicators of hospital activity: the length of acute hospital stay for surgical procedures and the use of day case surgery.

The existence of variations in health service activity raises questions as to whether they reflect differences in the needs of the populations served, or form an indicator of a failure to match needs and resources. This failure may involve an inappropriate under-use of resources among the low use groups if they fail to receive those services deemed to be appropriate for their health needs. Alternatively, an inappropriate use of services may occur among the high use groups if they receive services deemed to be "unnecessary" in terms of their health needs (eg, "unnecessary" surgical procedures, or "inappropriately" long lengths of stay. The matching of needs and resources thus has implications for the quality of health services and the outcomes achieved.

In economic terms, the deployment of resources may be regarded as inefficient to the extent that a given outcome may be achieved at less cost. For example, reducing length of stay or substituting day case surgery for inpatient admission may not affect the outcomes achieved for individual patients, but nevertheless may lead to considerable savings in terms of the health care resources required in their treatment, and is therefore more efficient. To the extent that such savings enable larger numbers of patients to be treated with a given level of resources (hospital beds, doctors, nurses, etc), the effectiveness of the health care system is increased. Questions of the appropriateness of resource use are thus central to the promotion of good quality, cost-effective care.

In this paper we first review the trends in length of stay and rates of day surgery, together with the prevailing between and within country variations. We then examine the causes of these variations and consider the implications of more innovative patterns of care. Finally we consider the ways in which changes in clinical practice style may be facilitated to promote greater efficiency.

Trends in length of stay and day case surgery

LENGTH OF STAY

The length of inpatient stay has shown a steady 
decline in most countries since the 1940s. This is illustrated by data for the Oxford region; the median length of stay in NHS hospitals in 19481957 was 9.9 days for appendicectomy and 15.0 days for cholecystectomy, but had declined to $7 \cdot 2$ days and $10 \cdot 0$ days respectively by $1978-83 .^{8}$ Data published in the Hospital In-Patient Enquiry (HIPE) since 1974 similarly show a continuing decline in mean length of stay for all specialities

Table I Mean durations of stay (days) for six procedures, England 1975-85

\begin{tabular}{lccc}
\hline Operative procedure & $1975^{\mathrm{a}}$ & $1980^{\mathrm{b}}$ & $1985^{\mathrm{c}}$ \\
\hline Tonsils and adenoids & $4 \cdot 0$ & 3.5 & 3.1 \\
Inguinal hernia & 7.3 & 5.7 & 4.9 \\
Appendix & 7.9 & $6 \cdot 2$ & 5.4 \\
Gall bladder & $16 \cdot 3$ & 13.6 & 12.2 \\
Prostatectomy & $19 \cdot 6$ & 14.0 & 11.2 \\
Hysterectomy & 14.4 & 11.8 & 10.2 \\
\hline a
\end{tabular}

a DHSS/OPCS Hospital In-patient Enquiry: main tables, 1975 (HMSO, 1978)

${ }^{6}$ DHSS/OPCS Hospital In-patient Enquiry: summary tables,

1980 (HMSO, 1983)

${ }^{c}$ DHSS/OPCS Hospital In-patient Enquiry: summary tables,

1985 (HMSO, 1987).

and age groups in NHS hospitals in England and Wales. This decline is illustrated in table I for six operative procedures.

The resource implications of a reduction in length of stay can be illustrated by comparing the changes in the numbers of patients treated and bed-days occupied. In England, 1985, there were 206 general surgery admissions per 100000 population compared with only 191 admissions in 1975. However the reduction in length of stay meant that on average only 18504 beds were used daily for general surgical patients in 1985, compared with 24348 in 1975.910

A similar trend of a declining length of stay has also characterised hospital use in the USA, ${ }^{11}$ although overall length of stay continues to be lower in the USA, so the relative gap between the two countries has been maintained. For example, in 1985, the average length of stay in the USA for inguinal hernia repair and appendicitis was 3.0 days and 4.9 days respectively ${ }^{12}$ compared with 4.6 and 5.4 days respectively in England and Wales. ${ }^{10}$

\section{DAY CASE SURGERY}

A surgical day case is a patient who is admitted for investigation or operation on a planned nonresident basis, and occupies for a period a bed in a ward or unit set aside for this purpose. The idea of hospital day case surgery is not new, although its modern development dates from the 1950s. Farquharson was an early exponent in Britain. In 1955 he reported on a series of 458 herniorrhaphies carried out on outpatients under local anaesthesia, rather than the then conventional 10-14 day inpatient stay. Among these, only 11 developed complications requiring admission. He thus advocated the widespread use of outpatient surgery, emphasising the therapeutic advantages of early mobilisation and its effect in reducing waiting lists. ${ }^{13}$ The use of day surgery expanded slowly in the UK during the $1960 \mathrm{~s}$, with several surgeons reporting their results. ${ }^{14} 15 \mathrm{~A}$ circular promoting day case surgery was issued by the Ministry of Health in 1967 and has since been advocated by a number of other government reports. ${ }^{16}$ In 1985 day case surgery was formally endorsed by the Royal College of Surgeons of England as an important element in surgical care and a booklet setting out the views of the Royal College on the scope of day case surgery and the facilities required was issued. ${ }^{17}$

Procedures recommended as suitable for day surgery are planned, clean surgical procedures which require a total operating time not exceeding 30 minutes. This includes a large number of minor procedures as well as a range of intermediate procedures, such as herniorrhaphy (simple inguinal, femoral, or epigastric hernia) and varicose vein ligation. Examples of procedures suitable for day case surgery in the specialities of general surgery, orthopaedic and hand surgery, urology, paediatric surgery, ophthalmic surgery, otolaryngology, plastic surgery, gynaecological surgery and oral surgery, are given in the Royal College of Surgeons guidelines. ${ }^{17}$ As the report notes, the excision of a variety of minor lumps which require only local anaesthetic can equally well be undertaken in an outpatient department, although it may be administratively easier to classify them as day cases. At the other extreme are intermediate surgical procedures which may sometimes be treated as day cases but often require inpatient admission.

The limiting factors in the selection of procedures as suitable for day case surgery, apart from the length of operating time, are whether the postoperative pain and discomfort can be relieved without recourse to injected analgesics after discharge from hospital, whether any skilled nursing care or management of dressings is required, and whether the procedure is likely to impair the patients' independence in respect of toilet functions. In terms of patient selection, the Royal College of Surgeons lists a number of criteria, including the age and fitness of the patient, housing amenities, the availability of another adult to provide care during the night as well as the day, availability of a telephone, and living within one hour's journey of the hospital. The Royal College of Surgeons estimates, for example, that in practice about a third of adult males between 18 and 65 with groin hernias can be safely treated on a day case basis; two thirds will be unsuitable for medical reasons, eg, obesity, diabetes, cardiovascular or respiratory disease, or for social and geographical reasons.

Although day case surgery has been practised for nearly 40 years and is advocated by government reports and by the Royal College of Surgeons, its adoption in the UK has been fairly slow. For example, it is estimated that the proportion of patients admitted as day cases increased from nine per cent of the acute caseload in 1974 to only $17^{\circ}{ }_{o}$ in $1986,,^{18}$ whereas the Royal College of Surgeons ${ }^{17}$ suggested that possibly one third of general surgical admissions in district general hospitals might be suitable for day case surgery. The Operational Research Unit of the North East Thames Regional Health Authority, using the Royal College of Surgeons guidelines, also estimated that day case surgery in the region could be increased from $17^{\circ}{ }_{0}$ to $38^{\circ}{ }_{0}$ of all general surgery. ${ }^{19}$ Estimates by a panel of anaesthetists and general surgeons of the proportion of 83 
procedures which could be performed on a day case basis similarly points to a considerable underuse of day case surgery in the UK. ${ }^{20}$

Day case surgery is more frequently performed in the USA than in the UK, although precise comparisons are difficult. This is partly due to problems in distinguishing between day case surgery and other ambulatory surgery. However, it is estimated that between 1979 and 1983 utilisation of hospital based ambulatory programmes in the USA increased by $86.5 \% .^{21}$ By $1985,81 \%$ of hospitals provided outpatient surgery, with outpatient surgical procedures representing $28 \%$ of total surgical procedures in American hospitals. ${ }^{22}$

An important development in the USA has been the growth of free standing surgical facilities (ie, outside the environs of a fully equipped hospital). One of the earliest free standing surgery centres was opened in Phoenix, Arizona, in 1970, with the name "Surgicenter". ${ }^{23}$ By 1985 there were 459 free standing surgical facilities in the USA undertaking nearly 800000 procedures per annum, with the projected figure for 1988 being 681 facilities undertaking 1.4 million procedures. $^{22}$ These facilities may be independently owned, part of a corporate chain, or occasionally associated with a hospital, and perform a limited range of minor surgical procedures. An analysis of the case load of the Phoenix Surgicenter showed the most common procedure undertaken was dilatation and curettage, followed by laparoscopy and myringotomy, adenoidectomy, cystoscopy and eye muscle operations. ${ }^{24}$ Day case surgery in the UK has been entirely provided within the environs of a hospital. Hospital based day surgery may take three main forms: (1) a self contained day surgery unit, (2) a day case ward, though patients go from it to the main operating theatre, and (3) day case beds in standard surgical wards.

\section{Explaining between country variations}

An important factor encouraging the general decline in lengths of stay and increase in day surgery has been the far reaching changes in clinical practice. These consist of changes in surgical techniques, as well as in suture material, anaesthesia, methods of pain control, the availability of new antimicrobial drugs and types of implant, etc. Major changes have also occurred in beliefs and practices regarding postoperative management, especially regarding the value of early ambulation. Changing views regarding postoperative care can be illustrated in relation to inguinal hernia repair, for which bed rest in a plaster frame for 6 weeks was recommended by Bassini in $1890 .^{25}$ During World War II the average time between a hernia repair and return to depot in the British army was 12 weeks and still included 6-7 weeks in bed. ${ }^{26}$ Since then earlier ambulation has increasingly been followed, with mean length of stay decling to $7 \cdot 3$ days in England by 1975 and to 4.9 days by 1985 (table I).

Although new technological developments and changes in professional views as to "good" clinical practices have encouraged the decline in length of stay and the greater use of day case surgery, the rate of adoption of these practices has varied between countries. An important factor contributing to these between country variations is the differences in the level of health service expenditure and methods of financing the delivery of health care. Hospitals in the NHS work on a fixed budget, which is largely determined by the size and age/sex structure of their catchment populations. A major concern is thus to keep spending within their total budget. There is little financial incentive to adopt short stay and day case surgery, because although these practices reduce costs per case, they are likely to lead to greater total costs and a possible budget overspend if they result in a greater throughput of patients. These budgetary consequences of increasing efficiency are referred to as the "efficiency trap". Another feature of the NHS is that hospital medical staff and managers are paid as salaried employees, although an element of performance related pay for hospital managers was introduced in 1984 as a means of increasing efficiency. There have thus been relatively few financial pressures or incentives on managers and clinicians in the NHS to achieve important budgetary constraints on activity through reduction in lengths of stay and higher rates of day surgery.

Pressures to increase throughput in the NHS have arisen from the increasing demands for hospital services and the waiting lists for elective surgery. This has recently led to proposals for the reform of the NHS, outlined in the White Paper "Working for patients".27 A central feature of these reforms is the encouragement of competition as a means of increasing efficiency. Thus while retaining a tax funded health service with budgets allocated to district health authorities, delivery of health care would be through internal markets based on competition between providers. Important aspects of this are that district health authorities would place contracts with hospitals for surgical services and would therefore compete on quality and price. To improve their chances of success in the market place, hospitals will therefore need to achieve greater efficiency with a view to reducing costs per case and hence increasing their price competitiveness. In addition, since revenue is related to contracts, increasing throughput would result in greater revenue, thus removing the efficiency trap. Other proposals for increasing competition are the provision for some hospitals to become self governing, as well as the encouragement of competition between NHS and private hospitals. However, as Robinson ${ }^{28}$ notes, "the White Paper provides a blueprint rather than a working model and leaves many questions unanswered, including how far competition will be allowed to develop and the form contracts will take." One issue is whether the proposed changes in financing although reducing costs per case will lead to a rapid escalation of total health care costs, as a result of an increased number of patients being treated. (For detailed critiques of proposed reforms see Bevan et al ${ }^{29}$ Kings Fund Institute; ${ }^{30}$ Quam; ${ }^{31}$ Robinson. ${ }^{28}$ )

In the USA, health care is mainly based on fee for service, with coverage being provided by third party payers. Since both physicians and hospitals are reimbursed at cost, as a fee for each service 
rendered, this has encouraged high rates of hospital admissions and procedures performed, and led to a rapid escalation of health service expenditure. ${ }^{32}$ As a result, various cost containment and regulatory measures have been introduced with the primary concern of reducing "unnecessary" hospital admissions and overtreatment. ${ }^{33}$ However, these measures have also influenced lengths of stay and rates of day case surgery. They include requirements for utilisation review of the patient's need for admission, appropriateness of services received and length of stay, and the more favourable coverage given by insurance carriers for ambulatory surgery compared with inpatient admission. ${ }^{34}$ While these mechanisms have formed general features of cost containment measures in American health care, they have assumed particular importance in relation to government funded programmes. Beginning in 1983 reimbursement of hospital charges for Medicare patients (over 65s and handicapped) has been based on a prospective payments system. This sets out a predetermined price for a particular type of care based on diagnostic related groups, which forms a method of classifying acute patients according to their diagnostic status into one of 468 categories. The introduction of prospective payment based on diagnostic related groups was important in severing the direct link between the provision of services and payment for them, and provided incentives for hospitals to be more efficient by reducing the lengths of stay and intensity of treatment, since this offered the reward of increased profits rather than reduced revenue. ${ }^{35}$. In addition, Medicare encouraged ambulatory surgery by providing favourable reimbursement rates for physicians. ${ }^{23}$ Another change in 1984 was that Professional Review Organisations replaced Professional Standards Review Organisations to monitor hospital use under the Medicare prospective payment system. Professional Review Organisations are regarded as agents of both cost containment and quality assurance and have specific objectives designed to achieve these aims. One of their objectives in reviewing admissions is to identify those who can safely and effectively be treated on an outpatient basis and thus shift care from inpatient to outpatient settings. ${ }^{36}$

These regulatory systems and methods of payment introduced from the early 1980 s appear to have been effective in reducing admission rates and lengths of stay in the USA. For example, it has been estimated that for the same case mix, lengths of stay for patients covered by Medicare were $25 \%$ lower in 1985 compared with 1980 , while hospital admissions of Medicare patients have fallen since 1983, although there has been little research examining the health outcomes of such changes. ${ }^{37}$

Another development in the USA which has been important in encouraging new patterns of practice has been the expansion of prepaid health care, in which a group of physicians provides comprehensive health services for a fixed prospective per capita payment to a defined population of members. There are various types of managed care, the most common being some form of Health Maintenance Organisation. By
1987 there were over 600 Health Maintenance Organisations with 27.7 million subscribers. ${ }^{38}$ Health Maintenance Organisations, unlike the fee for service system, integrate the financing and delivery of health care. They encourage the control of costs through operating within a fixed budget, while physicians often benefit from any surplus achieved. There are thus incentives to deliver cost effective care, with a need to work within a global budget and to offer a service which is attractive in terms of cost and quality so as to maintain a competitive position, although the element of competition between a Health Maintenance Organisation and other providers varies between areas. The precise impact of Health Maintenance Organisations is difficult to assess. However, it appears that they have achieved some cost savings, due mainly to lower rates of inpatient admission and a greater use of outpatient and ambulatory care. Health Maintenance Organisations may also have had a wider effect in forcing conventional insurers and providers to become more efficient by adopting these patterns of practice to maintain their market share. ${ }^{39} 40$

This brief outline identifies at a systems level some of the ways in which different methods of financing health care may contribute to the between country variations in rates of hospital use. While not intended as a comprehensive analysis, it suggests that whereas a fee for service system encourages high rates of hospital admission and procedures performed (including new high cost technologies), the introduction of financial and regulatory measures and price competitiveness can encourage a reduction of length of stay and a substitution of day case surgery for inpatient admission. However, whatever the system of health care, general trends have been the increase in hospital admission rates and the steady decline in lengths of stay. These trends have been encouraged by new technical developments and clinical practices, which have both increased the range of treatments available and enabled favourable outcomes to be achieved through a more cost effective use of resources, including a shorter length of stay and greater use of day case surgery.

\section{Within country variations}

So far the pattern identified is of a general trend characterised by a decline in length of stay and increased use of day case surgery, but of considerable variations between countries. Another important feature of hospital usage is the geographical variations which occur within countries.

The within country variations in length of stay have been noted in the UK over many years and were documented by Heasman ${ }^{41}$ and Logan et $a l .{ }^{42}$ More recently, an analysis of length of stay for appendicectomy, inguinal hernia repair, and cholecystectomy within regions of the UK showed there to be significant differences between districts after allowing for differences in the age distribution of patient populations, and excluding cases for which a second procedure was recorded as a proxy measure of severity. ${ }^{43}$ For example. $68 \%$ of admissions aged 45-64 years treated for inguinal 
hernia repair in the three shortest stay districts in South East Thames Regional Health Authority spent four days or less in hospital, compared with only $26 \%$ in the three longest stay districts. Similarly, $55 \%$ of cholecystectomy admissions aged 45-64 years spent eight days or less in hospital in the three shortest stay districts in the same region, compared with only $13 \%$ in the three longest stay districts. Comparisons of the observed length of stay with the regional average showed that for both procedures it was at least $13 \%$ above the regional average in the three longest stay districts, resulting in the occupancy of 2000 more bed days, and at least $13 \%$ below in the three shortest stay districts. These differences arose from differences in the length of both the preoperative and postoperative period. However, it is interesting to note that stays of 29 days or over accounted for only $3.5 \%$ of cholecystectomy admissions in the three longest stay district health authorities and $1.4 \%$ in the three shortest stay districts. This corresponds with the findings of other studies that the proportion of patients "blocking" beds in surgical wards is generally quite low, while the majority of longer stay surgical patients do not have stays exceeding one standard deviation of the expected stay. 4445

Within country variations in hospital use are also associated with different forms of health service funding. A recent trend in the UK has been the growth in elective surgery undertaken in the private sector, which now caters for about $16 \%$ of all elective surgery and over $30 \%$ in the Thames Regional Health Authorities. ${ }^{46}$ Williams et al $^{47}$ in an analysis of the median length of stay for eight "marker" operations, showed that length of stay was consistently shorter for patients in pay beds in NHS hospitals than for patients in either independent acute hospitals or in NHS public sector beds.

For example, the median duration of stay for inguinal hernia repair (age group 45-64) in each of these facilities was 4.4 days, 6.0 days and 5.9 days respectively. For cholecystectomy (age group 45-64) the median durations of stay were $9 \cdot 7$ days, 9.9 days and 10.7 days respectively. The pattern was similar for both preoperative and postoperative stay and for each age group examined. Differential use of other hospitals for part of the period of care did not explain this variation, with the exception of patients having hip replacement operations treated in NHS pay beds, of whom one in seven were transferred to public sector care postoperatively.

Rates of day case surgery, although still low in Britain, also vary between geographical areas. For example, in 1986, the proportion of general surgery conducted on a day case basis ranged between districts from $6 \%$ to $31 \%$ in South East Thames, $9 \%$ to $42 \%$ in Northern, $10 \%$ to $35 \%$ in Trent and $16 \%$ to $39 \%$ in Wessex. ${ }^{48}$ Similarly, Henderson et al $^{49}$ found in a comparison of day case surgery in five districts in Oxford Region during 1976-85 that the proportion of all female sterilisations conducted as day cases ranged from $<1 \%$ to $35 \%$, while dilatation and curettage varied from $1 \%$ to $43 \%$.

The observed variations in rates of hospital use raise questions of the reliability of the data. There is some evidence of an underrecording of inpatient procedures in the Hospital Activity Analysis, which has implications for the calculation of admission rates, as well as some variability in the recording and coding of specific items, especially diagnostic data. ${ }^{50}$ Problems of the quality and comparability of data between areas are probably greater for day case surgery, in view of the differences between hospitals in the ways in which day surgery is managed. For example, some procedures, such as gastroscopy and minor surgical excisions, may be treated as an outpatient procedure in some districts and a day case in others, depending on medical preference and local facilities, while in some hospitals little distinction may be made between an outpatient and a day case. As Hill ${ }^{51}$ notes, part of the apparent increase in rates of day case surgery may also be accounted for by a redefinition of cases that were previously counted as outpatients, without a change in management. This day case recording "drift" is encouraged by the setting of targets for day case surgery based on percentages of total case load. However, while acknowledging these problems of hospital statistics, they do not fully account for the observed geographical variations in hospital activity in the UK.

Despite the shorter length of stay in the USA there are still marked geographical variations. This was commented on by Chassin ${ }^{11}$ in a report prepared for the Office of Technology Assessment in which he states that "this phenomenon is the most striking of all variations in health service use that have been observed". He notes, for example, that in 1979 the average length of stay for Medicare patients varied from a high of 13.1 days in one New Jersey Professional Standards Review Organisation area to a low of 6.0 days in a Californian equivalent. In addition, over the past 15 years hospitals in the eastern USA have had lengths of stay that are about $40 \%$ higher than for hospitals in the western part of the USA, which cannot be accounted for by differences among regions in age, sex or race distributions.

Geographic variations also exist in ambulatory surgery. For example, in Syracuse, New York, a metropolitan area with a relatively limited supply of acute hospital beds (3.0 per 1000 population), $37 \%$ of all hospital based surgery was performed on an ambulatory basis in 1983, which was considerably higher than elsewhere in the USA. ${ }^{52}$ These geographical variations in lengths of stay and rates of day case surgery may again be influenced by differences in definition and recording. As in the UK, however, they are unlikely to be fully explained in these terms.

The general picture which emerges is therefore of national trends towards a shorter length of stay and increased use of day case surgery. However there continue to be important variations in patterns of surgical management within as well as between countries. At one end of the continum is the existence of lengths of stay which exceed a generally accepted norm and are substantially above the regional or national average. At the other end are patterns of care which involve considerably shorter stays than the current norm and a greater use of day case surgery. These findings raise questions of their causes and implications for the efficiency of resource use. 
Explaining within country variations The various groups of factors influencing lengths of stay are shown in the figure. One important issue is whether the relatively long length of stay in some areas can be accounted for by geographical variations in patients' needs, and hence can be viewed as appropriate or "acceptable", or whether it reflects an inappropriate or inefficient use of hospital resources.

\section{PATIENTS' NEEDS}

The contribution of geographical variations in morbidity to the observed variations in health service activity has been examined most fully in relation to the variations in hospital admission rates. ${ }^{53-55}$ This suggests that the large variations in admission rates cannot be fully accounted for by differences in the incidence of morbidity among population groups, and also reflects the influence of differences in health service provision and clinical practice styles. ${ }^{5356}$

Specific criteria for selection for day case surgery under the Royal College of Surgeons guidelines include the patients' general fitness and home circumstances. Similarly, the poor health state of deprived populations, and their less favourable housing conditions, can be viewed as producing the need for longer lengths of stay. However, there is the question of the extent to which differences in the medical and social characteristics of populations are translated into a greater use of hospital inpatient care.

A number of studies have provided some evidence of the influence of patients' characteristics on their length of stay. For example, a census of patients occupying beds in acute hospitals in one region in England showed some tendency for length of stay to increase with declining socioeconomic groups after controlling for level of bed provision. ${ }^{57}$ Similarly, an analysis of length of stay within selected diagnostic related groups at a hospital in Boston, Massachusetts, showed that lengths of stay were significantly longer for patients of lower socioeconomic status after adjusting for age, sex, severity of illness and the doctors' specialty. ${ }^{58}$ More detailed studies of the patient characteristics associated with relatively long length of stay have identified old age, disability, poverty, and a lack of carers as important factors. ${ }^{445}$ However, the influence of the social and medical needs of the population on length of stay often depends on local variations in health service provision, including the availability of alternative accommodation and the efficiency of discharge planning, as well as the extent to which clinicians take account of patients' social circumstances in their discharge decisions (figure).

\section{HEALTH SERVICE PROVISION}

A key factor identified as contributing to within country variations in length of stay is the influence of historical differences in the levels of health service provision between areas. Of particular importance is the supply of acute hospital beds, with a high level of supply being associated with a longer length of stay. ${ }^{5960}$ This is generally viewed as reflecting the effects of the level of pressure on beds in raising or lowering thresholds for discharge, as well as influencing the efficiency of organisation at a hospital level. However, the possibility of increasing efficiency and achieving a greater throughput of patients also depends on levels of finance, and the supply of other resources necessary to cater for the more intensive use of hospital beds, including staffing levels, the availability of operating theatre sessions, and other facilities. ${ }^{61} 62$

Length of stay in an acute hospital bed is influenced not only by the provision of services at a hospital level but also by the availability of alternative facilities, including convalescent and nursing homes, to provide continued nursing care, and by perceptions of the quality of general practitioner care in the area. The substantial geographical variations in the availability and use of alternative residential facilities is illustrated by an analysis of admissions for appendicectomy, inguinal hernia repair, and cholecystectomy in two regions in England. Overall less than two per cent of patients were transferred to convalescent hospitals and nursing homes on discharge from the acute hospital. However, in one district in each of the regions studied, over $20^{\circ}{ }_{0}$ of patients were transferred to another facility thus reducing their length of stay in an acute bed. ${ }^{63}$ Similarly, the availability of appropriate facilities and staffing for day case surgery encourages a substitution of day case for inpatient care.

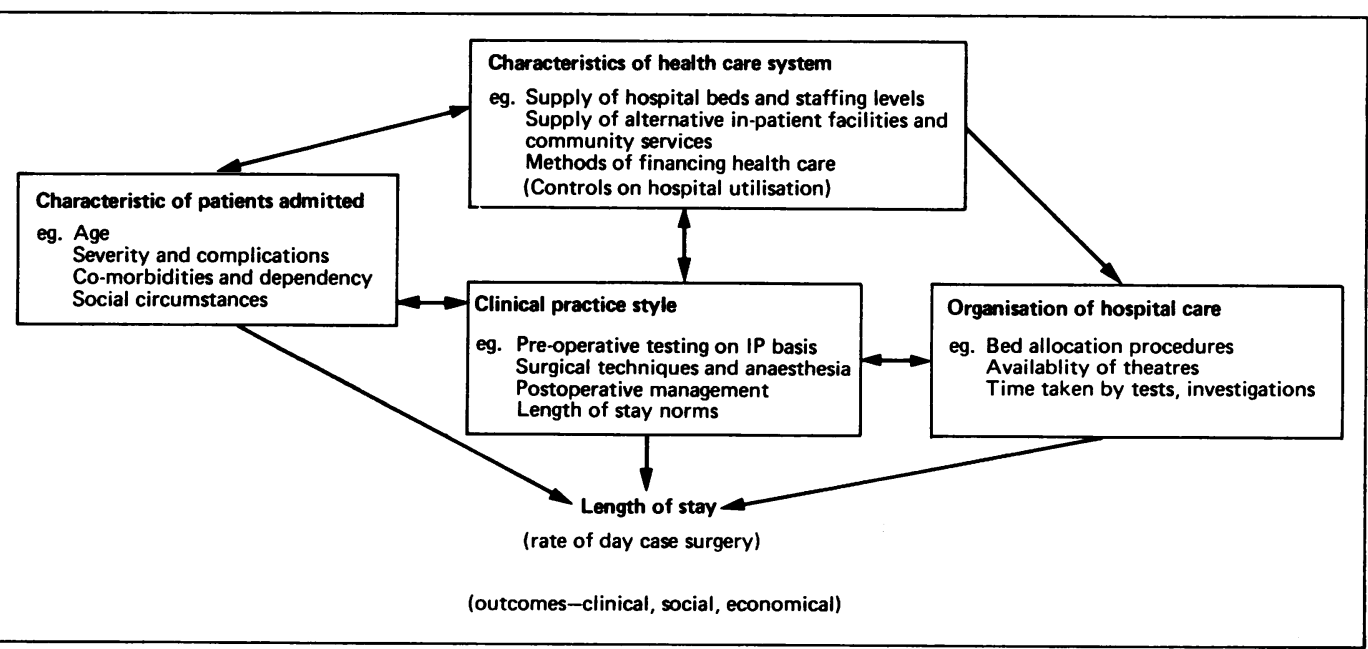


ORGANISATION OF CARE

The efficiency of organisation of care at a hospital level forms a product of the broader characteristics of the health care system, as well as of local circumstances and administrative arrangements (figure). Organisational practices which affect length of stay include the day and timing of admission, Friday and Saturday admissions leading to a longer stay, as do admissions after $3 \mathrm{pm},{ }^{64}$ while preadmission testing has the potential to reduce preoperative length of stay. ${ }^{65}$ The length of postoperative stay is dependent on the organisation of discharge; when discharge decisions are made at the consultant's ward round, the frequency of ward rounds can influence length of stay, ${ }^{66}$ while delays may also occur through the lack of early discharge planning, and through problems of arranging alternative accommodation or services required following discharge. ${ }^{6768}$ Other organisational factors include the turnaround time for laboratories and $x$ ray departments 6269 and the scheduling and management of theatres. ${ }^{70}$.

Assessments of the total amount of bed days that are occupied "unnecessarily" as a result of organisational inefficiencies have been based on reviews of individual patient's needs for hospital care. A recent study in the UK was undertaken by Anderson $e t$ al ${ }^{68}$ based on the review of a cohort of patients admitted to the John Radcliffe Hospital, Oxford, over a three week period. All medical, geriatric and surgical admissions were included apart from obstetrics, gynaecology, and admissions of children under 16. Patients' "need" to be in an acute hospital was assessed regularly using a bed study instrument. This identified nine criteria which justified acute hospital care. On this basis, only $38 \%$ of total bed days were regarded as being occupied by patients who had positive reasons for being in hospital. The figures ranged from $52 \%$ of patients in surgical beds to only $22 \%$ in geriatric beds. A major reason for the occupancy of a hospital bed in the absence of positive reasons, as judged using the bed study instrument, was the delay in discharge due to the need to await the consultant's ward round. The authors put forward a series of recommendations for reducing such delays. These included increasing the frequency of ward rounds at which discharge decisions are made, delegating responsibility for discharge decisions to other staff, and the use of discharge planning and diagnosis related protocols to plan length of stay.

A study adopting rather different criteria and methods of assessment was carried out by Beech $e t$ $a l^{71}$ based on the retrospective case record review of a random sample of medical and surgical admissions to a London teaching hospital. Admissions were assigned to five categories. These included the category "alternative" in which admission to an acute inpatient bed could have been avoided through day case procedures, outpatient investigations, nursing home care or a rehabilitation facility if such facilities were available. This "alternative" category accounted for $7.3 \%$ of surgical bed days, the majority consisting of cases who, on the basis of the Royal College of Surgeons guidelines, ${ }^{17}$ could have been treated as day cases. The authors also assessed whether a reduction in length of stay was possible through the better management of stay coupled with improved organisation of ancillary services, or through transfer to a non-acute unit, were this available. It was estimated that in total $14.8 \%$ of bed days could have been saved in these ways, with the greatest potential reduction being through the better management of stay.

Studies in the USA have similarly identified some scope for the more efficient management of patients, despite the systems of review and other controls on hospital use. ${ }^{72} 73$

\section{CLINICAL PRACTICE STYLE}

Clinical practice is influenced by current medical knowledge, the characteristics of the health system, and the organisation of care and facilities available at a hospital level. However variations between clinicians in their style of practice also make an independent contribution to variations in health service activity.

Wennberg and Gittelsohn ${ }^{74}$ cite various types of evidence of the effects of clinical practice style on rates of hospital use, including the findings from physician migration studies of the impact of one or two physicians on utilisation, and the effects that feedback of information can have in changing clinicians' practice style. However, some surgical procedures, including hip fracture and inguinal hernia repair, show much less variation in admission rates than hysterectomies, tonsillectomies and prostatectomies. ${ }^{7}$ This has been attributed to differences in professional uncertainty, or the degree of medical consensus regarding the clarity of diagnoses, efficacy of treatment, and timing of that treatment or procedure. Where considerable professional uncertainty exists, there is greater scope for professional judgement and choice, and hence for differences in clinical practice style.

Once patients are admitted, the clinical practices of individual clinicians may influence patients' lengths of stay through, for example, differences in the extent to which preoperative investigations are performed on an inpatient basis, and differences in the postoperative management of patients, including beliefs regarding early ambulation and length of stay norms. The contribution of differences in clinical practice style to variations in length of stay, as with admission rates, is likely to be least for those conditions and practices for which there is greatest consensus regarding surgical management and operative techniques, and which therefore present less scope for individual clinical judgement.

In some cases clinical practice style is constrained by the availability of facilities and services and the organisation of care at a hospital level. This was demonstrated in a study by Griffith et al, ${ }^{66}$ based on a review of 1086 patients admitted for elective hernia repair to eight hospitals in Wessex, 1970-71. There were shown to be highly significant differences in the mean postoperative stay between the nine consultants (3.5 to 7.9 days), although the hospital means varied even more ( 3.8 to 9.3 days). The mean postoperative stays for consultants operating at the same hospital were also similar in five of the six non-general practitioner hospitals studied. As the authors observe: "The results of the present 
study support the conclusion that the administrative procedures of the hospital imposed a similar stay on patients under the care of different consultant firms at the hospitals."

The scope for variations in clinical style is greatest in relation to the use of innovative practices, including short stay and day case surgery. Evidence of variation between clinicians in similar institutions in their use of day case surgery was provided by Roos ${ }^{75}$ in a study of outpatient surgery among patients aged 20 years or over in the eight largest hospitals in Manitoba, 1983-84. She showed there were large differences in rates of outpatient surgery between hospitals, which held even after adjustment for patient characteristics and differences in case mix. However, the range among surgeons was even greater. For example, in the hospital with the lowest rate of outpatient surgery, $18 \%$ of surgeons performed $95 \%$ or more of dilatation and curettage procedures on an outpatient basis, whereas nine per cent of surgeons performed less than $25 \%$ on an outpatient basis. The only difference between caseloads identified was that a rather higher proportion of patients treated by surgeons favouring outpatient treatment were resident in the region. Roos concludes that the "large differences in rates of outpatient surgery (is) likely to reflect physicians' preferences". She also notes that rates of day case surgery were lower among surgeons born in Britain compared with their North American colleagues. Such findings thus indicate that the use of day case surgery cannot be entirely explained in organisational terms, as reflecting differences in facilities and staffing (although this may itself be directly influenced by clinicians). Another important influence, particularly in terms of between hospital comparisons, is the differences in clinical styles and in the readiness of individual surgeons to adopt new forms of surgical management.

Surgical practices can be viewed as undergoing a gradual process of change. Thus at any one time there are likely to be groups of surgeons pioneering innovatory surgical techniques and forms of patient management, who may be gradually followed by others until such practices eventually become the norm. As Stocking ${ }^{16}$ notes, the rate of adoption of new technologies and clinical procedures, as with other innovations, is probably characterised by an $\mathrm{S}$ shaped diffusion curve. The earliest adopters can be classified as "innovators" who act as opinion leaders and are followed in terms of timing by "early adopters" and the "early majority". The "late majority" continue to be sceptical for a long period following the early uptake of the innovation, while the "laggards" continue their traditional practice. However, the rate of adoption, and hence the shape of the diffusion curve, varies for different innovations and is influenced by the perceived value of the innovation by the potential adopters (clinicians) and by those responsible at various levels for allocating resources and managing the service. Applying this to day case surgery and short stay policies, the slow rate of adoption of these practices can be attributed to their limited clinical advantages, with their main value being the cost savings achieved and freeing of resources, while the economic incentives for adopting these practices depends on the methods of financing and regulating hospital use.

The existence of geographical variations in patients' needs and the changing styles of clinical practice means that some within country variation in patterns of surgical management is to be expected at any one time. However, the existence of lengths of stay which are considerably above the average can be regarded as representing an inefficient use of acute beds. This is frequently associated with various types of organisational delays, including delays in effecting discharge, which may be due to problems of management as well as shortages of staff and other resources. At the other end of the continuum are small groups of surgeons with innovatory patterns of management involving short stays and high levels of day case surgery. The desirability of these patterns of surgical management requires an assessment of the clinical and social outcomes as well as the cost savings achieved.

The costs and outcomes of day case surgery are examined paying particular attention to the management of inguinal hernia repair, although the issues and assumptions raised are applicable more widely. Inguinal hernia repair forms an intermediate general surgical procedure for which a high proportion of cases are regarded as suitable for day case surgery by the Royal College of Surgeons of England. ${ }^{17}$ It comprises $12 \%$ of elective surgical procedures in the UK and is one of six elective procedures with the longest waiting times for surgery. ${ }^{76}$ In terms of resources it has been estimated on the basis of hospital costs per day that inguinal hernia repair costs the health service $£ 15$ million in England and Wales and $£ 40$ million in the USA at 1986 prices. ${ }^{77}$

\section{Costing studies}

Reductions in lengths of stay and the substitution of day case surgery for inpatient admission reduces hospital costs per case. However there are questions of the precise cost savings achieved and the existence of any "knock on" effects, or costs transferred to other caring bodies, such as district nurses, general practitioners, and home helps. Finally, there may be social costs (or savings) linked to the time patients and their families are absent from work.

\section{HOSPITAL COSTS}

The costs of day case surgery and inpatient care have been estimated using hospital billing, average costs and marginal costs. Varying assumptions have also been made as to the effects of releasing resources, which may be used either to generate savings or to increase overall caseload.

In the USA, where direct patient billing on an item for service basis is the norm, it is possible to compare the charges which patients pay for different durations of stay. This approach has been used to compare the costs of day case inguinal hernia repair with inpatient repair, with savings of $45-70 \%$ of the inpatient costs being reported for day case repairs. ${ }^{78-80}$ However, this difference in the cost figures partly reflects the economic stance of the institution, in terms of whether it is profit making or not, as well as the influence of regulatory bodies, such as Medicare. 
Another approach is to employ average costings. An example is a study by Burn, ${ }^{81}$ based on a review of the complete range of surgery in Southampton General Hospital. He listed procedures which he considered suitable for day case surgery and by an analysis of operating theatre records estimated that only $40 \%$ of the then current potential for day case surgery was being achieved. To assess the cost implications of an expansion of day case care, Burn used NHS per diem total average costs per inpatient day and per day case. Average costs were $£ 112.59$ per inpatient day and $£ 54.74$ per day case. Based upon an average length of stay for minor surgery cases of two days, Burn estimated that day case surgery provided a cost reduction of $75 \%$, giving a potential saving to the health authority of $£ 1 \cdot 27$ million if the full potential for day case surgery was realised. However his use of overall average costs which cover different levels and intensity of services does not adequately reflect individual patient cost profiles. In addition, many of the costs would remain fixed after an expansion of day care, at least in the short term, as the actual level of resources released, either to achieve savings or to expand the overall level of care, will depend primarily upon actual long term changes in staffing levels. In the short run possibly only hotel costs and non-pay costs such as drugs may be saved. When assessing the level of resources released within hospsitals from an expansion of day care, marginal costs rather than average costs are therefore required.

A detailed study involving a marginal costing approach was conducted by Russell et al $^{82}$ in 1972 and compared inpatient and day case care for inguinal hernia and haemorrhoids. The study population consisted of all patients requiring non-recurrent inguinal hernia and haemorrhoid repair over a one year period at North Tees General Hospital, Stockton-on-Tees. Patients were initially screened to remove any that were inappropriate for the trial because of their age, home circumstances or medical condition. Patients were then randomly allocated to day case surgery, or to an inpatient stay of five days for hernia patients and six days for haemorrhoid patients. The day case and inpatient groups were compared in terms of their clinical outcome, social effects and costs. Adopting a marginal costing approach, they estimated that the reduced requirement for bed days resulting from an expansion of day care made it possible to close a five bedded ward, leading to savings of $£ 25$ per case. A major benefit of day surgery is that by freeing inpatient beds it provides the opportunity to increase service levels. In this study, five beds could have been released. They therefore estimated what had been saved by avoiding the need to construct a new five bed ward. This led to savings of $£ 33$ per case on hospital services. By adopting a marginal approach to costing, this study thus predicted smaller potential savings from day surgery than the previous study by Burn. ${ }^{81}$

Beech and Larkinson ${ }^{83}$ also assessed the marginal cost savings for a hospital from the expansion of day care and reduced lengths of stay, based on general medicine and general surgery services in West Lambeth. They determined the savings from maintaining service levels in terms of caseload and standards of care with $15.9 \%$ fewer beds, which it had been estimated could have been released based on a previous case record review. ${ }^{71}$ Of these bed days released, $4.4 \%$ were from the expansion of day care, and the remaining $11.5 \%$ from policies to reduce lengths of stay by the removal of organisational delays. Using average costs they estimated that potential savings of $£ 2 \cdot 0$ million per annum could be achieved if nonpatient-related overheads were included, and $£ 1.4$ million per annum if they were excluded. However, on the basis of a detailed analysis of the costs and staffing levels that would actually vary if the efficiency gains were realised, they predicted annual savings of only $£ 214670$. These small savings stem from the assumption that hospital overhead costs will remain fixed, and with the exception of nursing costs, the costs associated with the treatment of patients will be unchanged. Remaining savings were related to "hotel" costs. The authors recognise that the scale of their estimated savings will vary according to local circumstances but they argue that their conclusion that the majority of costs remain fixed when beds are closed but services are maintained is generalisable. However the desire to reduce total costs may not be the motivation for introducing day case care. The expansion of day case surgery also frees inpatient beds, thus releasing the opportunity to increase total service levels.

The revenue consequences of increasing total service levels depend on the system of financing health care. In a system of fixed budgets, as has existed under the NHS, increasing throughput does not usually generate further revenue, with the result that an expansion of services can only be achieved through efficiency savings. In contrast, in a market situation where revenue is directly related to the numbers of cases treated, increasing throughput is not constrained in this way, while reducing length of stay and increasing day surgery will make a hospital more price competitive and increase its ability to attract patients. In addition, a greater caseload will mean that fixed and overhead costs can be apportioned across a greater number of patients and hence prices per case can fall.

Costing studies thus point to considerable savings at a hospital level through the reduction in length of stay, and more especially the substitution of day case for inpatient surgery. For example, costs of day case inguinal hernia repair are estimated to be between $30 \%$ and $60 \%$ of those of inpatient admission. However, the precise cost savings achieved at a hospital level depend on (1) the methods of deriving cost figures and items included, (2) the assumptions concerning the use of the bed days saved and whether the short or long run implications are considered, and (3) the levels of staffing and organisation of services. For example, a day theatre with a day case ward or five day ward attached offers much greater scope for staffing economies than when day cases are included in the main theatre list. High levels of theatre utilisation and low rates of unscheduled or cancelled sessions also help to spread overhead costs. Differences in levels of theatre utilisation are reflected in the 
varying hourly cost estimates for operating sessions. In a recent study of six hospitals in the UK the hourly cost for day surgical patients ranged from $£ 73.88$ to $£ 142.42$, with an average of $£ 107 \cdot 95$. $^{84}$ Other influences on the costs of day case surgery include whether local rather than general anaesthetic is employed and hence whether an anaesthetist is required.

\section{TRANSFERRED COSTS}

Surgical practices involving a short length of stay and greater use of day surgery, although reducing hospital costs per patient treated, may produce "knock on" effects for community services, such as district nurses and general practitioners. Empirical evidence of these knock on or transferred costs is fairly limited. In Burn's ${ }^{81}$ opinion, day surgery rarely places demands on these services. Conflicting evidence came from studies of intermediate surgical procedures by Russell $e a \mathbf{l}^{82}$ and Adler et al. ${ }^{85}$

Russell et $a l^{82}$ in their comparison of inpatient and day case care for the treatment of inguinal hernia and haemorrhoid patients, estimated that day case patients required an average of $4 \cdot 18$ more visits from district nurses and 0.5 more visits from general practitioners. At 1972 prices they estimated that these services cost $£ 4$ per day case, to be set against the savings at a hospital level of day case surgery of $£ 24$ to $£ 33$ per patient.

Adler et $\mathrm{l}^{85}$ assessed a policy of early discharge for patients requiring treatment for inguinal hernia and varicose veins in which patients were randomly allocated into two lengths of postoperative stay: 48 hours and 6-7 days. Short stay patients had lower inpatient costs but higher costs associated with general practitioner, district nursing and home help services. The total cost of these services for long stay inguinal hernia patients was $£ 4 \cdot 88$ and for short stay $£ 9 \cdot 31$, a cost difference of $£ 4.43$. For varicose vein patients these costs totalled $£ 5 \cdot 26$ for long stay patients and $£ 11.92$ for short stay, a difference of $£ 6.66$ per case. These higher costs are quite large when set against savings per case on hospital services calculated by Adler et al of $£ 32.64$ for inguinal hernia patients and $£ 29.84$ for varicose vein patients. Adler and his colleagues also found that short stay patients had a longer period of convalescence. They estimated the production losses of this longer time to return to normal duties as being $£ 19.40$ per patient higher for hernia cases and $£ 4.33$ per patient higher for varicose vein cases.

These studies emphasise the importance of taking account of any transferred costs when assessing the savings achieved by short stay or day case surgery. Requirements for nursing care and medical services following discharge have however decreased since the 1970s when these studies were undertaken, as a result of changes in the surgical techniques and methods of suture employed. In addition, there have been important developments in the preoperative preparation of day case patients which may increase their ability to manage after discharge. Nevertheless, the issue of transferred costs is often raised and identifies a need for studies to assess the transferred costs currently associated with day case surgery for intermediate procedures. There is also a need for studies costing different forms of organisation of day case surgery, in terms of the facilities and staffing levels employed.

\section{THROUGHPUT AND WAITING LISTS}

The extent to which day surgery is forming a substitute for inpatient care or merely increasing the total surgical throughput has been examined based on the experience of a small number of centres including Kingston Hospital in Surrey, which introduced a six bedded day surgical unit in $1979 .^{86}$ Three relatively major proceduresinguinal hernia repair, varicose veins and partial mastectomy-comprised $26 \%$ of all procedures treated in the unit and about seven percent of all surgical operations. However, the authors noted that for all operative procedures with the exception of three (partial mastectomy, cystoscopy and inguinal hernia repair among patients aged 15-44) increasing day surgery rates were superimposed on steady or increasing inpatient rates. However, only for varicose veins was there an increase in patients from outside the district. Adding day surgery thus increased the total throughput of patients over a given period. This contrasts with the views of Lagoe and Milliren $^{52}$ who suggested that in New York State the difference between the highest inpatient rates $(67 \cdot 1$ per 1000 population) and the lowest $(45 \cdot 6$ per 1000 population) might be explained by a significant substitution of inpatient for ambulatory procedures. However, it should be noted that the lowest inpatient admission rate was more than twice that for England. Thus only when a population is adequately or even overprovided can day surgery become a substitute for inpatient care. In a situation where there are waiting lists for surgery an important effect of introducing day surgery can be to reduce waiting times. This has its greatest effect for patients requiring elective procedures, including inguinal hernia repair, varicose veins, hip replacement, cataract and haemorrhoids, who often have the longest waiting times because others with more acute or serious conditions are added to the operating list ahead of them. ${ }^{8788}$

\section{Clinical and social outcomes}

The minor surgical procedures which form the majority of surgical day cases are likely to produce few increased clinical risks compared with inpatient care, so long as the fairly well established criteria of patient selection are followed and appropriate care is given. Day case surgery for such procedures also appears to be associated with considerable patient satisfaction. ${ }^{89} 90$ However, there are important questions of the clinical and social outcomes of day case surgery for inguinal hernia repair and other intermediate procedures, as well as of substantial reductions in length of stay. The effects of short stay policies are examined paying particular attention to the management of cholecystectomy. This is one of the eight most commonly performed surgical procedures and is thus responsible for significant numbers of bed days. Calculations based on the per diem cost of hospital bed days suggests that this procedure cost the health service $£ 23$ million in England and Wales and $£ 72$ million in the USA 
in 1986 , representing $13 \%$ and $16 \%$ respectively of the total costs for eight common elective procedures. ${ }^{77}$

Examples of studies evaluating the clinical and/or social outcomes of day case and short stay surgery for inguinal hernia and cholecystectomy are summarised in table II. These studies have involved controlled trials, with either a random allocation of patients to care groups or the identification of matched pairs (Nos 1-5), as well as uncontrolled trials based often on a review of patients treated by a single surgeon (Nos 6-11).

\section{CLINICAL OUTCOMES}

Mortality rates are extremely low for most elective surgical procedures, whether conducted as an inpatient procedure or day case. ${ }^{91}$ It is therefore necessary to focus on other indicators of morbidity and quality of care. One of the main clinical outcomes employed is the experience of complications. The general conclusion drawn from the studies summarised in table II is that short stay and day case surgery has no significant effect in increasing risks of complications. However, this assessment is often based on the more major complications. A greater incidence of minor problems, such as persistent oozing of the wound, infected wounds, chest infection, etc, although sometimes described, are often not regarded as detracting from clinical outcomes. ${ }^{859293}$ The relatively small numbers of patients generally studied also mean that unless differences between groups are fairly large they are unlikely to reach statistical significance.

The other main measures of clinical outcomes employed are rates of recurrence and readmissions. In terms of recurrence for inguinal hernia repair, a review of operations performed on a day case basis at one hospital identified $4.2 \%$ recurrences at 34 months, defined as "the presence of an expansile cough impluse". 94 They noted that their recurrence rate lies within the range for inpatient repairs but planned to adopt the Shouldice operation based on the experience of Glasgow ${ }^{95}$ and Devlin et $a l^{96}$ with a view to lowering their recurrence rate still further.

Readmission rates tend to be fairly low among patients undergoing elective surgical procedures. However readmission rates form an important clinical outcome among elderly medical patients, with a substantial proportion of readmissions being classified as "avoidable".97 98

The general conclusion drawn by these evaluative studies is that short stay policies and day case surgery for inguinal hernia repair and other selected surgical procedures have little impact on clinical outcomes, although in some cases the presence of higher rates of minor short term complications was noted. However, short stay and day case surgery is generally applied selectively, with these results thus relating to particular categories of patients. Other important factors influencing the outcomes achieved are the specific surgical techniques employed and the use of local or general anaesthesia, ${ }^{969-100}$ as well as the experience and expertise of surgeons in undertaking the procedure.

Continuing developments in surgical techniques and expertise may mean that more favourable outcomes are currently being achieved than were demonstrated by earlier evaluations. Rather than continuing to focus on comparisons of day case and inpatient surgery, or short and longer lengths of stay, it is thus important to conduct evaluations and more informal reviews to identify optimal clinical practices in the conduct of these forms of surgical management.

\section{SOCIAL OUTCOMES}

This has mainly been assessed in terms of patient's satisfaction with their care. The majority of patients express a high level of satisfaction, although several studies showed that a significant proportion of patients undergoing day case surgery for inguinal hernia repair and varicose veins would have preferred inpatient care (table II). Similarly, a significant proportion of the cholecystectomy patients reviewed by Reder et $a l^{93}$ would have preferred a longer period of hospital care. However, the reasons for this preference and the strength of the preference are rarely described. There is also the question of the trade offs that patients are willing to make where there are waiting lists for surgery. For example, the choice between a shorter length of stay and an early operation or a longer length of stay and a greater waiting time (or between immediate day case surgery and waiting for inpatient care), may result in a preference for the more immediate care option. Patients' anxiety and preferences will also be influenced by their actual experiences of short stay and day case surgery. This emphasises the importance of evaluating patients' satisfaction with different forms of preoperative preparation and of examining particular causes of anxiety and dissatisfaction, with a view to improving the management of these forms of care.

In conclusion, the studies reviewed in table II suggest there is some, but not a significant, increase in risks of complications for selected surgical procedures undertaken on a day case rather than an inpatient basis, or under a very short compared with a longer length of stay. Similarly, they show that although patient satisfaction is generally high, a small proportion of patients undergoing these innovative patterns of surgical management would have preferred a longer stay. The clinical and social outcomes achieved are however likely to vary over time and between hospitals, and they are influenced by three broad groups of factors. These are: (1) clinical, eg, the specific surgical techniques and anaesthesia employed, the skill of the surgeon, operating time, and postoperative care; (2) organisational, eg, the type of day case facilities employed, the adequacy of communication with patients, relatives, general practitioners and nurses, and provision for admission if required; and (3) patient selection, eg, severity of patients' clinical condition, general fitness and psychological state, their housing conditions and availbility of care at home.

In view of the considerable experience which has now been gained in the management of day case and short stay surgery for intermediate procedures, it is important to review the experiences and practices of innovative sugeons in terms of each of these variables to determine how far a consensus is emerging as to optimal patterns of management. 
Table II Studies examining clinical and social outcomes associated with reduction in LOS and/or day case surgery for selected surgical procedures

\begin{tabular}{|c|c|c|c|c|}
\hline Authors & Study design & Clinical criteria & Social criteria & Results \\
\hline $\begin{array}{l}\text { 1. Russell et al } \\
(1977)^{82}\end{array}$ & $\begin{array}{l}\text { Random allocation of } 132 \\
\text { selected inguinal hernia and } \\
63 \text { haemorrhoids patients to } 8 \\
\text { hours postop LOS, and } 5-6 \\
\text { days postop LOS }\end{array}$ & $\begin{array}{l}\text { Complications } \\
\text { Readmission rate } \\
\text { Length of convalescence }\end{array}$ & $\begin{array}{l}\text { Preferred LOS } \\
\text { Time off work by family } \\
\text { members }\end{array}$ & $\begin{array}{l}\text { No significant differences in } \\
\text { complications after hernia } \\
\text { repair but greater } \\
\text { complications among short } \\
\text { stay than longer stay } \\
\text { haemorrhoids. Significant } \\
\text { proportion of day cases would } \\
\text { have liked overnight stay. No } \\
\text { other significant differences in } \\
\text { social measures }\end{array}$ \\
\hline $\begin{array}{l}\text { 2. Adler et al } \\
(1978)^{85}\end{array}$ & $\begin{array}{l}\text { Random allocation of } 105 \\
\text { inguinal hernia and } 119 \\
\text { varicose veins patients aged } \\
18-64 \text { h to } 48 \text { postop and } \\
6-7 \mathrm{~d} \text { postop }\end{array}$ & $\begin{array}{l}\text { Complications } \\
\text { Rate of recurrence } \\
\text { Length of convalescence }\end{array}$ & $\begin{array}{l}\text { Satisfaction of patient and } \\
\text { family with LOS }\end{array}$ & $\begin{array}{l}\text { No significant differences in } \\
\text { major complications or in } \\
\text { recurrence rates but longer } \\
\text { convalescence for shorter stay. } \\
\text { Significant number of families } \\
\text { of short stay patients would } \\
\text { have preferred a longer stay } \\
\text { but no differences for patients }\end{array}$ \\
\hline $\begin{array}{l}\text { 3. Garraway et al } \\
(1978)^{111}\end{array}$ & $\begin{array}{l}\text { Random allocation of } 360 \\
\text { selected hernia and varicose } \\
\text { vein patients to } 3 \text { groups: } \\
\text { (a) } 2 \text { d acute ward, (b) } 2 \text { d } \\
\text { convalescent ward, (c) day } \\
\text { case with GP and district } \\
\text { nurse support }\end{array}$ & - & Views of patient and carer & $\begin{array}{l}10^{\circ} \text { of patients and } 20^{\circ}{ }^{\circ} \\
\text { carers in day case group } \\
\text { expressed preference for } \\
\text { longer stay }\end{array}$ \\
\hline $\begin{array}{l}\text { 4. Marks et al } \\
(1980)^{90}\end{array}$ & $\begin{array}{l}\text { Retrospective review of } \\
\text { hospital admissions and day } \\
\text { case surgery for } 10 \text { procedures } \\
\text { in prepaid group practice for } \\
\text { period } 1967-74\end{array}$ & Provider satisfaction & $\begin{array}{l}\text { Patient satisfaction with } \\
\text { quality of care }\end{array}$ & $\begin{array}{l}\text { Providers satisfied with } \\
\text { ambulatory care. } \\
93^{\circ} \text { ambulatory patients and } \\
88^{\circ} \text { inpatients satisfied with } \\
\text { quality of medical care } \\
\text { received }\end{array}$ \\
\hline $\begin{array}{l}\text { 5. Reder et al } \\
(1983)^{93}\end{array}$ & $\begin{array}{l}\text { Retrospective view of case } \\
\text { notes for cholecystectomy } \\
\text { patients. Patients classified as } \\
\text { short stay ( } 6 \text { d or less) or } \\
\text { conventional stay ( } 7-10 \mathrm{~d} \text { ) and } \\
\text { matched for preop LOS; } \\
\text { presence of secondary } \\
\text { diagnosis, age and sex. } 18 \\
\text { pairs identified }\end{array}$ & $\begin{array}{l}\text { Complications up to } 2 \text { years } \\
\text { following surgery }\end{array}$ & $\begin{array}{l}\text { Patient satisfaction with care } \\
\text { and attitude to LOS }\end{array}$ & $\begin{array}{l}\text { Significantly higher } \\
\text { proportion of short stay } \\
\text { patients thought LOS too } \\
\text { short. } \\
\text { No other significant } \\
\text { differences between groups }\end{array}$ \\
\hline $\begin{array}{l}\text { 6. Pineault et al } \\
(1985)^{112}\end{array}$ & $\begin{array}{l}\text { Patients undergoing tubal } \\
\text { ligation, hernia repair and } \\
\text { meniscectomy selected in } \\
\text { terms of severity of condition, } \\
\text { general fitness and age, and } \\
\text { then randomly assigned to day } \\
\text { case or IP case (n }=182 \text { ) }\end{array}$ & $\begin{array}{l}\text { Patients view of discomfort } \\
24 \mathrm{~h} \text { after operation } \\
\text { Reporting of surgical } \\
\text { problems } \\
\text { Complications recorded in } \\
\text { case notes }\end{array}$ & Patient satisfaction with LOS & $\begin{array}{l}\text { No significant differences in } \\
\text { clinical outcome. Over half } \\
\text { day cases thought LOS too } \\
\text { short and significant } \\
\text { proportion would have } \\
\text { preferred IP care }\end{array}$ \\
\hline $\begin{array}{l}\text { 7. Goldbourne and } \\
\text { Ruckley }(1979)^{92}\end{array}$ & $\begin{array}{l}\text { Review of } 1055 \text { patients for } \\
\text { inguinal or femoral hernia or } \\
\text { varicose veins selected for day } \\
\text { case surgery. No comparison } \\
\text { group. }\end{array}$ & $\begin{array}{l}\text { Timing of discharge } \\
\text { Complications assessed at } \\
\text { clinic visits or reported by } \\
\text { community nurse } \\
\text { Readmission rate }\end{array}$ & - & $\begin{array}{l}\text { Planned discharge delayed for } \\
2 \cdot 5^{\circ} \text { patients; } 1^{\circ} \text { o patients } \\
\text { readmitted; } 25^{\circ} \text { experienced } \\
\text { some complications, mainly } \\
\text { wound problems }\end{array}$ \\
\hline $\begin{array}{l}\text { 8. Cannon et al } \\
(1982)^{113}\end{array}$ & $\begin{array}{l}\text { Review of } 104 \text { admissions for } \\
\text { inguinal hernia. Identified } 54 \\
\text { patients for } 48 \text { h postop stay } \\
\text { and further } 40 \text { for discharge } \\
\text { prior to or on } 4 \text { th preop day } \\
\text { (ie, } 94 \text { patients in early } \\
\text { discharge group) }\end{array}$ & $\begin{array}{l}\text { Timing of discharge } \\
\text { Complications }\end{array}$ & Patient satisfaction with LOS & $\begin{array}{l}\text { Planned discharge delayed for } \\
40^{\circ} \text { of patients, including } \\
44^{\circ}{ }^{\circ} \text { of proposed } 48 \text { hour } \\
\text { postop stay. } 10^{\circ} \text { patients } \\
\text { dissatisfied with time of } \\
\text { discharge }\left(2^{\circ}{ }^{\circ} \text { thought their }\right. \\
\text { LOS was too long and } 8^{\circ}{ }_{\circ} \text { too } \\
\text { short) }\end{array}$ \\
\hline $\begin{array}{l}\text { 9. Rockwell } \\
(1982)^{78}\end{array}$ & $\begin{array}{l}\text { Review of } 50 \text { hernia patients } \\
\text { selected for day case surgery. } \\
\text { No comparison group }\end{array}$ & $\begin{array}{l}\text { Timing of discharge } \\
\text { Complications } \\
\text { Recurrence rate }\end{array}$ & - & $\begin{array}{l}42 \text { of } 50 \text { patients returned } \\
\text { home same day. Two } \\
\text { discharged patients returned } \\
\text { with complications. } \\
\text { No recurrences }\end{array}$ \\
\hline 10. Moss $(1986)^{114}$ & $\begin{array}{l}\text { Consecutive series of } 100 \\
\text { elective cholecystectomy } \\
\text { patients discharged within } \\
24 \text { h following operation. } \\
\text { No comparison group }\end{array}$ & - & $\begin{array}{l}19 \text { patients interviewed by } \\
\text { nurse }\end{array}$ & $\begin{array}{l}\text { Two patients with } \\
\text { complications and } 3 \\
\text { readmitted. } \\
\text { Judged successful form of care } \\
\text { by surgeon. } \\
95^{\circ} \text { of patients satisfied with } \\
\text { early discharge }\end{array}$ \\
\hline 11. Hall $(1987)^{115}$ & $\begin{array}{l}\text { Consecutive series of } 100 \\
\text { elective simple } \\
\text { cholecystectomies. Discharge } \\
\text { on second postop day accepted } \\
\text { by } 77 \text { patients. } \\
\text { No comparison group }\end{array}$ & $\begin{array}{l}\text { Timing of discharge and } \\
\text { complications among } 77 \text { short } \\
\text { stay patients }\end{array}$ & Patient satisfaction with LOS & $\begin{array}{l}27^{\circ} \text { o patients electing for } \\
\text { short stay would have } \\
\text { preferred longer postop stay. } \\
66^{\circ} \text { of eligible patients } \\
\text { discharged on second postop } \\
\text { day. } \\
\text { No readmissions or deaths } \\
\text { within } 30 \mathrm{~d} \text { of operation. }\end{array}$ \\
\hline
\end{tabular}




\section{Changing clinical practice styles}

This review has identified scope for increasing the efficiency of surgical management through a greater use of short stay policies and day case surgery, as well as the reduction of the relatively long lengths of stay in some hospitals which do not appear to be justified by patient needs. This raises questions of the barriers to be overcome and requirements for increasing the efficiency of surgical management. One set of barriers consists of the constraints on clinical practice that exist at a hospital level and which arise from the organisation and financing of hospital services as well as from local conditions, such as the age and social circumstances of patients and the distribution of beds and staffing between specialties. However, there are also questions of the factors influencing individual clinical practice styles and the readiness of clinicians to adopt innovative forms of surgical management.

Clinicians may often lack awareness as to how their practices differ from current norms. This has probably been particularly true in the UK, where there has been little feedback to clinicians of data on which to assess their practice. However small groups of surgeons have established their own data base using microcomputers to review performance, with a view to identifying problems and producing changes in clinical management. In some cases this review has been limited to the activities of a single firm. ${ }^{101-103}$ In other cases comparisons have been made across hospitals. ${ }^{104} 105$

Clinical barriers limiting the adoption of day case surgery or short stay policies may also arise if surgeons do not regard such forms of management as having any clinical advantages. For example, surgeons frequently question the desirability of day case surgery for intermediate procedures, despite the results of evaluative studies and the endorsement of these practices by professional bodies. Reluctance to adopt these practices may also reflect the considerable uncertainty experienced as to precisely how innovative practices should be implemented locally, as well as a feeling of unease with unfamiliar forms of patient management, including for example the use of local anaesthesia for inguinal hernia repair. Greer, ${ }^{106}$ on the basis of interviews with physicians in the United States and Britain, suggests that these clinical concerns partly arise from the inadequate way in which scientific journals deal with clinical needs. This arises from a neglect of clinically important data, in terms of information on indicators and clinical outcomes, risks and complications, as well as details of the specific procedures and facilities which contributed to the outcomes reported. Greer found that of greater importance in the diffusion of new techniques was the information and confidence gained from contacts with local innovators and opinion leaders, as well as the opportunity provided by meetings of specialty societies to converse with those with "hands on" experience.

Other perceived disadvantages which may be associated by surgeons with day surgery include its effect on the balance of their workload. In the UK, the adoption of day case surgery, particularly for intermediate procedures, means that surgeons of consultant grade are often involved in undertaking large numbers of procedures that would otherwise be performed by non-consultant staff on an inpatient basis. As a result, the most experienced surgeons are not able to perform other more complex or interesting procedures. However, others question this view and argue that non-consultant staff can be trained to achieve a high level of competence in performing inguinal hernia repair and other intermediate procedures on a day case basis. They also suggest that day case surgery can be organised so that it does not disrupt medical student teaching.

The measures adopted to achieve changes in clinical practice styles have varied between countries, reflecting the broader characteristics of their health care systems. For example, in the US there has been considerable reliance on regulatory approaches and financial penalties for departures from explicit standards. In contrast, in Britain the emphasis has been on encouraging and facilitating improvements in clinical management and the achievement of more cost effective care. This has included methods of increasing the involvement of clinicians in resource decisions in the NHS through clinical budgeting and resource management initiatives in which clinicians participate formally in decisions about the use of resources. ${ }^{107}$ Proposals contained in the White Paper for influencing clinical management include not only the changes in the financing of health service delivery but also a commitment to giving clinicians a greater role in the management of hospitals. ${ }^{27} \mathrm{~A}$ central role is also assigned to medical audit in promoting good quality, cost effective care. This involves provision for external audit, through the ability of management to initiate an independent professional audit, if for example there is cause to question the quality or cost effectiveness of a service, as well as through the creation of an independent Audit Commission. However, major emphasis is given to a more informal system of internal audit in which clinicians review their own practices. The Royal College of Surgeons ${ }^{108}$ describes this review as a "process by which medical staff collectively review, evaluate, and improve their practice". It is proposed that this form of medical audit should be set up in each specialty and involve every hospital doctor. Such peer review is regarded as providing a forum for discussion and may lead to improved education of staff, quality of care, outcome of care, and process of care. Where guidelines have been developed or targets set, these can form important standards by which performance can be assessed. However, even in the absence of explicit standards, medical audit does establish a framework for the identification of variations in process and outcomes, and the discussion of areas of concern, as well as assisting in identifying ways in which performance can be improved. The active involvement of clinicians in the audit process has been shown to have a much greater effect in changing physicians' behaviour than more passive feedback of data. ${ }^{109}$

Whereas this section has focused on the achievement of changes in surgeon's practice styles, such changes also frequently have implications for anaesthetists and the composition and level of workload of nursing staff. It is thus 
important that attention is given to these wider implications, as well as to the acceptability and satisfaction with services among patients, which provides an important indicator of quality of care.

\section{Conclusions}

Variability in length of stay for surgical procedures is a continuing pattern that occurs both between and within countries. The between country variation is strongly influenced by differences in methods of funding health care delivery and the incentives or constraints this provides for reducing length of stay and substituting day case surgery for inpatient admissions. The within country variations largely reflect the influence of local circumstances in terms of levels of bed provision, the organisation of care at a hospital level and the availability of community services, as well as the independent effect of differences in clinical practice styles which are a product of the considerable clinical autonomy that exists. This suggests that so long as clinical decision making affords scope for individual judgement and choice, some variation in the management of surgical patients will form a continuing feature of health care.

The main rationale for advocating a reduction in length of stay and increased use of day case surgery is that this reduces costs per case, with little if any reduction in the outcomes achieved, and so enables more patients to be treated with a given level of resources. However, as this review indicates, the precise cost savings achieved through a greater use of day case surgery depend on the costing assumptions made and the facilities employed. Only in relation to intermediate surgical procedures, such as inguinal hernia repair, are there important questions of clinical desirability and patient acceptability of day case surgery, while reductions in lengths of stay only raise such issues when lengths of stay considerably shorter than the current norms are proposed.

Scientific evaluations suggest that the clinical outcomes achieved and levels of patient satisfaction for short stay and day case surgery do not differ significantly from more traditional patterns of patient management. However, there are questions of the importance attached to any differences identified. In addition, the outcomes achieved are likely to vary as a result of differences in surgical techniques and in the management of care, including the criteria of patient selection and the adequacy of the preoperative communication and preparation of patients in reducing anxiety. Thus whereas previous evaluations have indicated that such practices do not significantly reduce the outcomes achieved, there is now a need to compare different methods of organising day case surgery and to establish optimal patterns of surgical management in terms of clinical techniques, patient selection and the organisation of care.

The relatively slow rate of adoption of day case surgery in the UK can be attributed to a lack of financial incentives and regulatory mechanisms promoting this form of patient management. In addition, day case surgery carries little intrinsic interest for the majority of surgeons. This raises the question of whether a greater specialisation within surgery should be encouraged, in view of the differing demands involved in undertaking intermediate procedures on a day case basis.

Given the choice, many patients in Britain would probably currently prefer inpatient admission for intermediate surgical procedures, although choosing day case treatment for minor excisions. However, evidence from the USA suggests that the more widespread practice of inguinal hernia repair as a day case in that country has led to its greater acceptance among patients, with many now preferring not to be admitted as an inpatient. ${ }^{110}$ Thus just as clinical practices change over time, so also do patients' expectations and preferences.

Mechanisms for encouraging the widespread adoption of efficient forms of surgical management will necessarily vary between countries, reflecting the differences in the organisation and funding of their health care systems. However, it is important to ensure that financial incentives and other mechanisms designed to achieve cost savings do not lead to a reduction in the standards of care. This requires that outcomes are closely monitored. An important aspect of this is the review of patient acceptability and satisfaction with care which might be monitored on a routine basis as a means of quality assurance.

We would like to thank our colleagues for helpful comments on earlier drafts and especially Tony Swan, Larry Seidl, Gwyn Bevan, Stirling Bryan and Brendan Devlin.

This review, including publication costs, was financed by the Department of Health as part of a larger project examining variations in surgical practice. The authors alone are responsible for the views expressed.

1 Eisenberg JM. Doctors' decisions and the cost of medical care. Michigan: Health Administration Press Perspectives, 1986.

2 Dowie R. General practitioners and consultants: a study of outpatient referrals. London: King's Fund Institute, 1983.

Vayda E. Comparison of surgical rates in Canada and in England and Wales. $N$ Engl $\mathcal{F}$ Med 1973; 289: 1224-9.

4 McPherson K, Strong PM, Epstein A, Jones L. Regional McPherson K, Strong PM, Epstein A, Jones L. Regional
variations in the use of common surgical procedures: variations in the use of common surgical procedures:
within and between England and Wales, Canada and the within and between England and Wales, Canada and the
United States of America. Soc Sci Med 1981; 15A: 273-88.

5 McPherson $K$, Wennberg JE, Hovind OB, Clifford $P$ Small-area variations in the use of common surgical procedures: an international comparison of New England England and Norway. N Engl f Med 1982; 307: 1310-4

6 Wennberg JE, Barnes BA, Zubkoff M. Professional uncertainty and the problem of supplier-induced demand Soc Sci Med 1982; 16: 811-24.

7 Wennberg JE, Freeman JL, Culp WJ. Are hospital services rationed in New Haven or over-utilised in Boston? Lance 1987; i: $1185-8$.

8 Coulter A, McPherson K. Waiting times and duration of hospital stay for common surgical operations: trends over

9 DHSS/OPCS. Hospital inpatient enquiry, 1975 (main tables). London: Her Majesty's Stationery Office, 1978.
.

10 DHSS/OPCS. Hospital inpatient enquiry, 1985 (summary tables). London: Her Majesty's Stationery Office, 1978.

11 Chassin M. Variations in hospital length of stay: their relationship to health outcomes. Health Technology Case Study 24. Washing DC: Office of Technology Assessment, 1983.

12 Department of Health, Education and Welfare. Vital and health statistics, series 13. 1985: No. 69. Washington DC, 1987

13 Farquharson EL. Early ambulation with special reference to herniorrhaphy as an outpatient procedure. Lancet 1955 ii: 517-9.

14 Stephens FO, Dudley HAF. An outpatient organisation for outpatient surgery. Lancet 1961; i: 1042.

15 Morris D, Ward A, Hardiside AJ. Early discharge after hernia repair. Lancet 1968; i: 681-5.

16 Stocking B. Initiative and inertia: case studies in the NHS London: Nuffield Provincial Hospitals Trust, 1985. 
17 Royal College of Surgeons of England. Commission on the provision of surgical services: guidelines for day case surgery. London: Royal College of Surgeons, 1985.

18 NHS. NHS hospital activity statistics for England 1974 86. Stat Bull 1987; 5: 87.

19 Bates T, Hamm J. Data unto the day patient. Health Serv $\mathcal{F}$ 1989; 2 March: 266.

20 Gabbay J, Francis L. How much day surgery? Delphic predictors. Br Med f 1988; 297: 1249-52.

21 Lagoe RJ, Bice SE, Abulencia PB. Ambulatory surgery utilization by age level. Am f Public Health 1987: 77: 33-7.

22 Riffer J. Can surgicenters stand alone? Hospitals 1986; July 20: 44-8.

23 Ermann D, Gabel J. The changing face of American health care: multihospital systems, emergency centres and surgery centres. Med Care 1985; 23: 401-20.

24 Lairson D, Baron A, Surint JM, Greenlick MR, Marks SD. Do-not-admit versus inpatient surgery in an HMO: determinants of choice and the implications for medical care costs. Health Serv Res 1980; 15: 378-96.

25 Bassini E. Uber die Behandlung des Leitenbruches. Arch Klin Chir 1890; 40: 429-39 (Quoted in Morris GE, Jarrett PE. f R Coll Surg Lond 1987; 69: 97-9).

26 Edwards $H$. Inguinal hernia. Br $\mathcal{f}$ Surg 1943; 31: 172-85.

27 Secretaries of State for Health, Wales, Northern Ireland and Scotland. Working for patients. (CM555) London: Her Majesty's Stationery Office, 1989.

28 Robinson R. New health care market. Br Med $\mathcal{F} 1989$; 298 : 437-9.

29 Bevan G, Holland WW, Mays N. Working for which patients at what cost? Lancet 1989; i: 947-9.

30 Kings Fund Institute. Managed competition: a new approach to health care in Britain. Briefing Paper No. 9. approach to health care in Britain. Briefr

31 Quam L. Improving clinical effectiveness in the NHS: an alternative to the White Paper. $\mathrm{Br} M e d f$ 1989; 299: 448-50

32 Quam L. Post-war American health care: the many costs of market failure. Oxford Rev Econ Policy 1988; 5: 113-23.

33 Schroeder SA. Strategies for reducing medical costs by changing physicians behaviour. Int $\mathcal{F}$ Technol Assess 1987; 3: $39-50$.

34 Feldstein PJ, Wickizer TM, Wheeler JRC. Private cost containment. N Engl f Med 1988; 318: 1310-4.

35 Bevan G. Reforming UK health care: internal markets or emergent planning. Fiscal Studies 1989; 10: 53-71.

36 Dans PE, Weiner JP, Otter SE. Peer Review Organisations: Dans PE, Weiner JP, Otter SE. Peer Review Organisations:
promises and pitfalls. $N$ Engl f Med 1985; 313: 1131-7.

37 Schramm CJ, Gabel J. Prospective payment: some retrospective observations. $N$ Engl $f$ Med 1988; 318: 1681-2.

38 Rayner G. HMO's in the USA and Britain: a new prospect for health care? Soc Sci Med 1988; 27: 305-20.

39 Luft HS. How do Health Maintenance Organisations achieve their savings? New Engl f Med 1978; 298: 1336-43.

40 Luft T. Competition and regulation. Med Care 1985; 23: 383-400

41 Heasman MA. How long in hospital? A study in variation in duration of stay for two common surgical conditions. Lancet 1964; ii: $539-41$

42 Logan RFL, Ashley JSA, Klein RE, Robson DM Dynamics of medical care: the Liverpool study into use of
hospital resources. Memoir No. 14. London: London hospital resources. Memoir No. 14. London:
School of Hygiene and Tropical Medicine, 1972.

43 Morgan M, Paul E, Devlin HB. Length of stay for common surgical procedures: variation among districts. $\mathrm{Br} \mathcal{f}$ Surg 1987; 74: 884-9.

44 Seymour DJ, Pringle R. Elderly patients in a general surgical unit: do they block beds? $B r$ Med $\mathcal{f}$ 1982; 284: 1921-3.

45 Coid J, Crome P. Bed blocking in Bromley. Br Med f 1986; 292: $1253-6$.

46 Nicholl JP, Beeby NR, Williams BT. Role of the private sector in elective surgery in England and Wales, 1986. Br Med F 1989; 298: 243-6.

47 Williams BJ, Nicholl JP, Thomas KJ, Knowleden J. Differences in durations of stay for surgery in the NHS and private sector in England and Wales. Br Med $\mathcal{F}$ 1985; 290: 978-80.

48 Department of Health and Social Security. Performance indicators for the NHS. London, 1987.

49 Henderson J, Goldacre M, Griffith M, Simmons HM. Day case surgery: geographical variations, trends and readmission rates. F Epidemiol Community Health 1989; 43: 301-5.

50 Butts MS, Williams DRR. Accuracy of hospital activity analysis data. $\mathrm{Br}$ Med $\mathcal{F} 1982$; 285: 506-7.

51 Hill A. Day cases: what are we counting? Community Med 1988; 180-5.

52 Lagoe RJ, Milliren JW. A community based analysis of ambulatory surgery utilisation. Am $\mathcal{F}$ Public Health 1986; 76: $150-3$.

53 Sanders D, Coulter A, McPherson K. Variations in hospital admission rates: a review of the literature. London: King's Fund Institute, 1989.

54 Blumberg MS. Inter-area variations in age adjusted health status. Med Care 1987; 25: 340-53.

55 Wennberg JE. Population illness rates do not explain population hospitalisation rates. Med Care 1987; 25: 354-9.

56 Morgan M, Mays N, Holland WW. Can hospital use be a measure of need for health care? $\mathcal{f}$ Epidemiol Community Health 1987; 41: 269-74.
57 North East Thames Regional Health Authority. Patient census study: social factors analysis. NETRHA census study: social factors analysis.

58 Epstein AM, Sterns RS, Tognetti J, et al. The association of patients' socio-economic characteristics with the length of hospital stay and hospital changes within diagnosticrelated groups. $N$ Engl $f$ Med 1988; 318: 1579-85.

59 Feldstein MS. Hospital bed scarcity: an analysis of the effects of inter-regional differences. Economica 1965; 32 393-409.

60 London Health Planning Consortium. Acute hospital services in London: a profile by the London Health Planning Consortium. London: Her Majesty's Stationery Office, 1979.

61 Ro KK. Patient characteristics, hospital characteristics, and hospital use. Med Care 1969; 7: 295-312.

62 Eastaugh SR. Organisational determinants of surgical lengths of stay. Inquiry 1980; 17: 85-96.

63 Morgan $M$. Variations in length of stay at district level. Chapter 3. In: Ham C, ed. Health care variations: assessing the evidence. London: King's Fund Institute, 1988

64 Babaro DM, Shuman LJ, Swinkola RB. An evaluation of various pre-surgical testing procedures. Inquiry 1977; 14 369-83.

65 Cannoodt LJ, Knickman JR. The effects of hospital characteristics and organisational factors on pre- and post-operative lengths of hospital stay. Health Serv Res 1984; 19: 561-85.

66 Griffiths M, Water WE, Acheson ED. Variation in hospital stay after inguinal herniorrhaphy. $\mathrm{Br}$ Med $\mathcal{f} 1979$;

67 Cable EP, Mayers SPJ. Discharge planning effect on length of hospital stay. Arch Phys Med Rehabil 1983; 64: 57-60.

68 Anderson P, Meara J, Brodhurst S, Attwood S, Timbrell M, Gatherer A. Use of hospital beds: a cohort study of admissions to a provincial teaching hospital. $\mathrm{Br}$ Med $f$

69 Ferrow LC, McColl I, Mackie. Firm, patient and process variables associated with length of stay. $\mathrm{Br} M e d \mathcal{F} 1978$; 556-9.

70 Robbins JA, Donaldson LJ. Analysing stages of care in hospital stay for fractured neck of femur. Lancet 1984; ii: 1028-9.

71 Beech R. Challah S, Ingram RH. Impact of cuts in actue beds on services for patients. Br Med f 1987; 294: 685-88.

72 Restuccia J. The effect of concurrent feedback in reducing inappropriate hospital utilisation. Med Care 1982; 20: 46-62.

73 Sui AL, Sonnenberg FA, Manning WG. Inappropriate use of hospitals in a randomized trial of health insurance plans. $N$ Engl $f$ Med 1986; 315: 1259-66.

74 Wennberg JE, Gittelsohn A. Variations in medical care among small areas. Sci Am 1982; 246: 100-12.

75 Roos NP. What is the potential for moving adult surgery to the ambulatory setting? Can Med Assoc $\mathcal{f}$ 1988; 138 :

76 Donaldson L, Pugh EJ, Smyth EJ. A census of patients waiting for treatment or consultation in surgical specialities in an English health region. Community Med 1989; 11: 13-20.

77 McPherson K. Variations in hospitalisation rates: why and how to study them. In: Ham C, ed. Health care variations assessing the evidence. London: Kings Fund Institute, 1988.

78 Rockwell E. Outpatient repair of inguinal hernia. $A m \mathcal{J}$ Surg 1982; 143: 559-60.

79 Coe RC. Changing methods best way to cut costs. Am Med News 1981; 24: 5 .

80 Flanagan L, Bascom JU. Herniorrhaphies performed on outpatients' under local anaesthesia. Surg Gynecol Obstet 1981; 153: 557-60.

81 Burn JM. Responsible use of resources: day surgery. $B r$ Med $₹$ 1983; 286: 492-93.

82 Russell IT, Devlin HB, Fell M, Glass NJ, Newell DJ. Day-case surgery for hernias and haemorrhoids: a clinical, social and economic evaluation. Lancet 1977; ii: 844-7.

83 Beech R, Larkinson J. Estimating the financial savings from maintaining the level of acute services with fewer hospital beds. London: Department of Community Medicine UMDS, St Thomas' Campus, 1989.

84 NHS Management Executive VFM Unit. The managemen and utilisation of operating departments. London, 1989.

85 Adler MW, Waller JJ, Creese A, Thorne SC. Randomise controlled trial of early discharge for inguinal hernia and varicose veins. F Epidemiol Community Health 1978; 32 136-42.

86 Haworth E, Balarajan R. Day surgery: does it add to or replace inpatient surgery? $\mathrm{Br} M e d \mathcal{f} 1987$; 294: 133-5.

87 Rainey JB, Ruckley CV. Work of a day unit. Br Med $\mathcal{f} 1979$ ii: 714-7.

88 Lakhani S, Leach RD, Jarrett PEM. Effect of a surgical day unit on waiting lists. $\mathcal{F} R$ Soc Med 1987; 80: 628-9.

89 Jensen J, Jackson B. Consumers prefer same-day surgery to inpatient care for minor procedures. Modern Healthcare 1985; 15: 76-8.

90 Marks S, Greenlick MR, Hurtado A, Johnson J Henderson J. Ambulatory surgery in an HMO: a study of costs, quality of care and satisfaction. Med Care 1980;18: $127-46$

91 Buck N, Devlin HB, Lunn JN. Confidential enquiry into perioperative deaths. Association of anaesthetists of Great Britain and Ireland. London: Nuffield Provincial Hospitals Trust/Kings Fund, 1987. 
92 Gouldbourne IA, Ruckley CV. Operations for hernia and varicose veins in a day-bed unit. $B r$ Med $f$ 1979; ii: 712-14.

93 Reder VA, Fineberg HV, Rosoff C, White LS. Shorte length of stay for simple cholecystectomy: costeffectiveness of alternative strategies. Med Care 1983; 21 : 745-54.

94 Morris GE, Jarrett PE. Recurrence rates following local anaesthetic day case inguinal hernia repair by junior surgeons in a district general hospital. Ann Surg Eng 1987; 69: 97-9.

95 Glassow F. Short stay surgery (Shouldice technique) for repair of inguinal hernia. Ann $R$ Coll Surg Lond 1976; 58 : repair

96 Devlin HB, Russell IT, Muller D, Sahay AK, Tiwari PN. Short stay surgery for inguinal hernia: clinical outcome of the Shouldice operation. Lancet 1977; i: 847-9.

97 Graham H, Livesley B. Can readmissions to a geriatric medical unit be prevented? Lancet 1983; i: 404-6.

98 Williams EI, Fitton F. Factors affecting early unplanned readmission of elderly patients to hospital. $\mathrm{Br} \mathrm{Med} \mathcal{F} 1988$; 297: 784-7.

99 Glassow $F$. Inguinal hernia repair using local anaesthesia. Ann R Coll Surg Lond 1984; 66: 382-7.

100 Devlin HB. Management of abdominal hernia. London: Devlin HB. Manage

101 Dunn DC. Audit of a surgical firm by microcomputer: five years experience. $\mathrm{Br} M$ Med $\mathcal{F}$ 1988; 296: 687-91.

102 Sellu DP, Benjamin IA, Lynn JA. Audit: its effect on the performance of a surgical unit in a district general hospital. Hosp Health Serv Rev 1986; 82: 64-9.

103 Irving M, Temple J. Surgical audit: one year's experience in a teaching hospital. Br Med F 1976; ii: 746-7.
104 Gilmore OJA, Griffiths NJ, Connolly JC, et al. Surgical audit: comparisons of the workload and results of two audit: comparisons of the workload and results of two 105 Gruer R, Gordon DS, Gunn AA, Ruckley CV. Audit of surgical audit. Lancet 1986; i: 23-5.

106 Greer AL. The state of the art versus the state of the science: the diffusion of new medical technologies into practice. Int $\mathcal{F}$ Technol Assess Health Care 1988; 4: 5-26.

107 Wickings I, Coles JM, Flux R, Howard L. Review of clinical budgeting and costing experiments. $\mathrm{Br}$ Med $\mathcal{F}$ 1983; 286: 575-8.

108 Royal College of Surgeons. Guidelines to clinical audit in surgical practice. London: Royal College of Surgeons, 1989.

109 Mitchell MW, Fawkes FGR. Audit reviewed: does feedback on performance change clinical behaviour? $\mathcal{F} R$ Coll Physicians Lond 1985; 19: 251-4.

110 Wantz GE. Ambulatory hernia surgery. Br ₹ Surg 1989; 76 : 1228-9.

111 Garraway WM, Cuthbertson C, Fenwick N, Ruckley CV, Prescott RJ. Consumer acceptability of day care after Prescott RJ. Consumer acceptability of day care after
operations for hernia and varicose veins. $₹$ Epidemiol operations for hernia and varicose

112 Pineault R Constandriopoulos AP, Valois M, Bastion ML Pineault R, Constandriopoulos AP, Valois $M$, Bastion ML,
Lance JM. Randomized clinical trial of one-day surgery. Med Care 1985; 23: 171-88.

113 Cannon SR, Ralphs DN, Bolton JP, Wood JJ, Allen A Early discharge following hernia repair in unselected patients. Br f Surg 1982; 69: 112-3.

114 Moss G. Discharge within 24 hours of elective cholecystectomy. Arch Surg 1986; 121: 1159-61.

115 Hall RC. Short surgical stay: two hospital days for cholecystectomy. Am $\mathcal{F}$ Surg 1987; 154: 510-5. 